\title{
INVESTIGATION OF CONTACT FATIGUE AND OPERATING PERFORMANCE OF NI-WC COMPOSITE ELECTROCOATED GEARS
}

KETAN BHAT, MANEESH AVADHANI, MILIND GURAV, VADIRAJ PATIL, M. KRISHNA

Student, Department of Mechanical Engineering, R.V. College of Engineering, Bengaluru-59

Email: ketanbhat.rv@gmail.com

Student, Department of Mechanical Engineering, R.V. College of Engineering, Bengaluru-59

Email: maneesh.avadhani@gmail.com

Student, Department of Mechanical Engineering, R.V. College of Engineering, Bengaluru-59

Email: milindgurav.mg@gmail.com

Student, Department of Mechanical Engineering, R.V. College of Engineering, Bengaluru-59

Email: vadiraj0606@gmail.com

Research \& Development, Department of Mechanical Engineering, R.V. College of Engineering, Bengaluru-59

Email: krishna_phd@gmail.com

\section{ABSTRACT}

The objective of the work was to evaluate contact fatigue and operating performance of electrodeposited Ni-WC composite coated gears using experimental technique. The electrodeposited Ni-WC coating was characterized for coating thickness, hardness and crystal structure using Electro-Physik gauge, Rockwell Hardness testing machine and X-Ray Diffraction respectively. The operation condition was estimated using designed test rig and vibration pick with CRO. The results show that coated gears are smoother in operation and offer more resistance to wear and fretting due to increased hardness.

\section{Keywords}

Contact fatigue, composite coated gears, Ni-WC coating

\section{Academic Discipline And Sub-Disciplines}

Science and Engineering, Mechanical Engineering

\section{SUBJECT CLASSIFICATION}

Fatigue and Vibration Analysis

\section{TYPE}

Engineering and Experimental study

\section{Council for Innovative Research}

Peer Review Research Publishing System

Journal: Journal of Social Sciences Research

Vol. 8, No.1

jssreditor.cir@gmail.com

www.jssronline.com 


\section{INTRODUCTION}

Extensive use of transmission gears in machineries demands improvement of fatigue life of gears. At present, Carburizing, Nitriding, Physical Vapor Deposition and chemical vapor deposition are some of the most adopted techniques to improve surface hardness of gears [1]. Electrodeposition is considered as one of the most important and cost effective industrial techniques for producing protective coatings [2]. Deposition of $\mathrm{Ni}$ has been proved to improve wear and corrosion resistance [3]. Presence of WC in Ni-WC composite coating increases the nucleation sites to reduce the crystal size leading to a more uniform coating while imparting hardness to the surface. [4-5] Electro-coating process has key controlling factors such as temperature and $\mathrm{pH}$ of the electrolyte, distance between electrodes, whose values were chosen from previous research work [6] to optimize uniform coating thickness.

Contact fatigue results from a Hertzian stress state which is a localized stress state that results when curved surfaces are in contact under a normal load. The contact geometry and the motion of the rolling elements produce an alternating subsurface shear stress [7]. Subsurface plastic strain builds up with increasing cycles until a crack is generated. After the onset of surface pitting the operation of the rolling elements becomes rough and noisy. The crack further propagates deteriorating the operation condition. Study has proved that lubrication may encourage cracks at this stage [8]. Two meshing gears transmitting power experience surface fretting due to contact fatigue. These can be detected by changes in amplitude pattern of the system [9-11]. Though composite coatings have been extensively used for industrial applications it is seldom used for surface property enhancement of gears. Insufficient research has been done towards the design of apparatus to evaluate contact fatigue performance of transmission gears.

The objective of this work is to evaluate the contact fatigue performance of gears that have been coated with $\mathrm{Ni}$-WC composite. The comparison of the smoothness of operation of the coated and non-coated gears is done using vibration analysis.

\section{EXPERIMENTAL WORK}

For electro-coating of Ni-WC composite, distilled water with reagents mentioned in Table 1 was used. Electrolyte was prepared and $200 \mathrm{ml}$ of the same was taken in another flask. It was added with reinforcement particles and ultrasonicated for one hour at $37 \mathrm{KHz}$ for proper wetting and dispersion of particles. It is then added to electrolytic solution and stirred continuously using magnetic stirrer for uniform distribution. $\mathrm{pH}$ was adjusted using sodium-Hydroxide ( $\mathrm{NaOH})$ to the optimized value of 3.7. Coating was carried for 2 hours for each specimen.

Table 1: Composition of chemicals and operating parameters

\begin{tabular}{|c|c|cc|}
\hline Chemical Name & Quantity (g/L) & \multicolumn{2}{|c|}{ Operating Parameters } \\
\hline Nickel Sulphate $\left(\mathrm{NiSO}_{4} \cdot 6 \mathrm{H}_{2} \mathrm{O}\right)$ & $225-300$ & Temperature & 3.7 \\
\hline Nickel Chloride $\left(\mathrm{NiCl}_{2} \cdot 6 \mathrm{H}_{2} \mathrm{O}\right)$ & $30-45$ & $\mathrm{pH}$ & $0.5 \mathrm{~A}$ \\
\hline Boric acid $\left(\mathrm{H}_{3} \mathrm{BO}_{3}\right)$ & $40-50$ & Current & 120 min \\
\hline Tungsten Carbide $(\mathrm{WC})$ & 3 & Time & \\
\hline
\end{tabular}

Initially, the electrodeposition was carried out on MS sample plate to characterize the coating because it is not possible for coating on gears. X-Ray Diffraction method is used for characterization. XRD Maxima- 7000 X-Ray Diffractometer is used for this purpose. Two theta Angle was varied from 10-90 degrees in the steps of 4 degree/ min.

The test gears were applied with masking tape on the area where the coating of the material was not necessary. Only the area of tooth surface is exposed for coating. Same electroplating procedure is followed for gears. Coating thickness measurement was carried out using Electro-Physik gauge. Hardness was measured by Rockwell Hardness Tester using cone indenter at a load of $150 \mathrm{kgf}$.

For accurate rolling contact conditions between the two teeth surfaces, suitable equipment was designed for testing and assembled. It consisted of an electric motor to drive the gear, gearbox for required speed reduction, the driven gear and pulley for applying torque. Table 2 explains the gear parameters. Figure 1 shows the CAD model of test rig. The main components were, (1) Electric Motor (2) Coupling (3) Gearbox (4) Driver Gear (5) Driven Gear (6) Bearing Support (7) Pulley (8) Rope drive. Torque can be varied by suspending different loads at the rope drive end. During experimentation, the torque was varied in the steps of $0,0.44,0.74,0.88,1.32 \mathrm{Nm}$.

Vibration measurement was carried out using vibration pick-up device connected to CRO. Tektronix TDS $2002 \mathrm{~B}$ digital storage $\mathrm{CRO}$ was used for the purpose. The readings in the form of Excel sheets and waveform images were taken after each hour till the end of fourth hour for each torque. 
Table 2: Gear specifications

\begin{tabular}{|c|c|}
\hline Type & Spur Gear \\
\hline Material & EN 31 \\
\hline Module & $2.5 \mathrm{~mm}$ \\
\hline Number of teeth & 52 \\
\hline Facewidth & $20 \mathrm{~mm}$ \\
\hline PCD & $130 \mathrm{~mm}$ \\
\hline Addendum & $2.5 \mathrm{~mm}$ \\
\hline Dedendum & $3.125 \mathrm{~mm}$ \\
\hline Speed & $24 \mathrm{rpm}$ \\
\hline
\end{tabular}
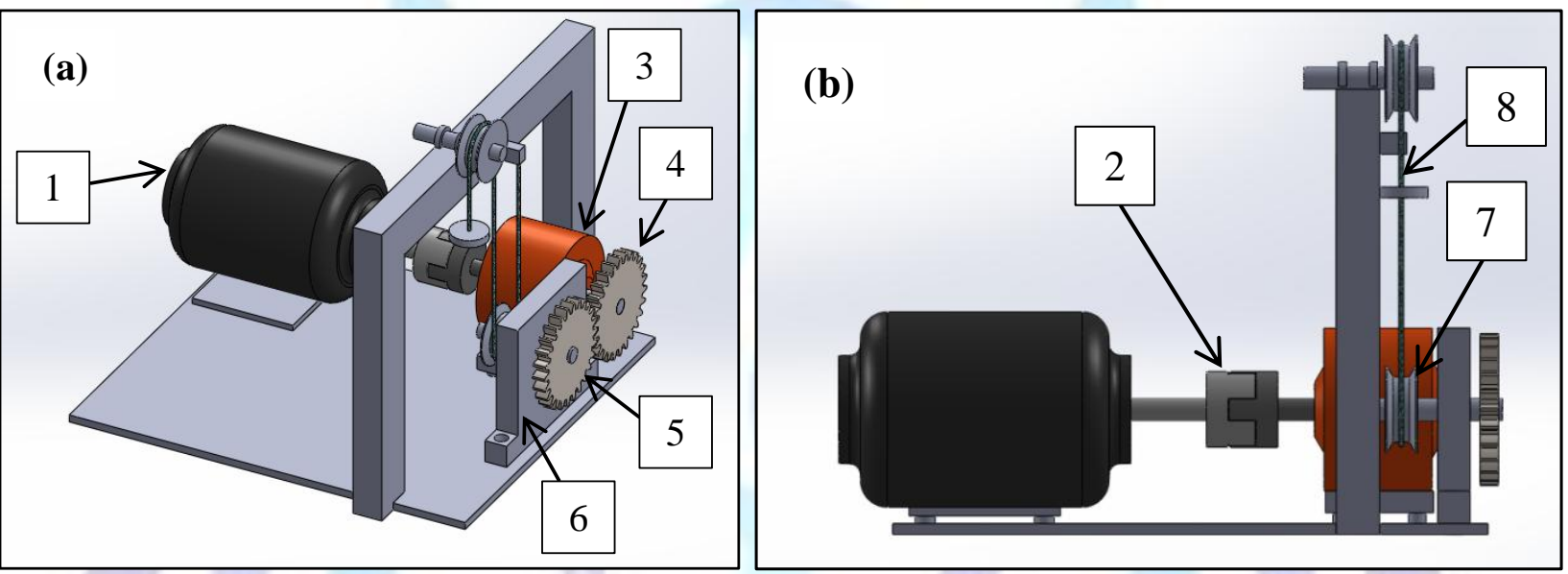

Figure 1: Schematic of test rig used for experimentation with all the components (a) Isometric view (b) Front View

\section{RESULT AND DISCUSSION}

\subsection{Characterization}

Coating thickness measurement of gear tooth surface with electro-physic gauge indicated average thickness values of 62 $\mu \mathrm{m}$ and $63 \mu \mathrm{m}$ for driver and driven gears respectively. An $8 \%$ increase in surface hardness value was observed in the $\mathrm{Ni}-$ WC coated gears. The non-coated gears had a hardness of $105.5 \mathrm{HRC}$ and the coated gears had 113.75 HRC.

\subsection{Vibration Analysis}

Vibration analysis done using the test rig provides a comparison of vibration amplitudes of coated and non-coated gears during operation.

Block diagram of the test set up with vibration pick up sensor connected to CRO is shown in Figure 2. 


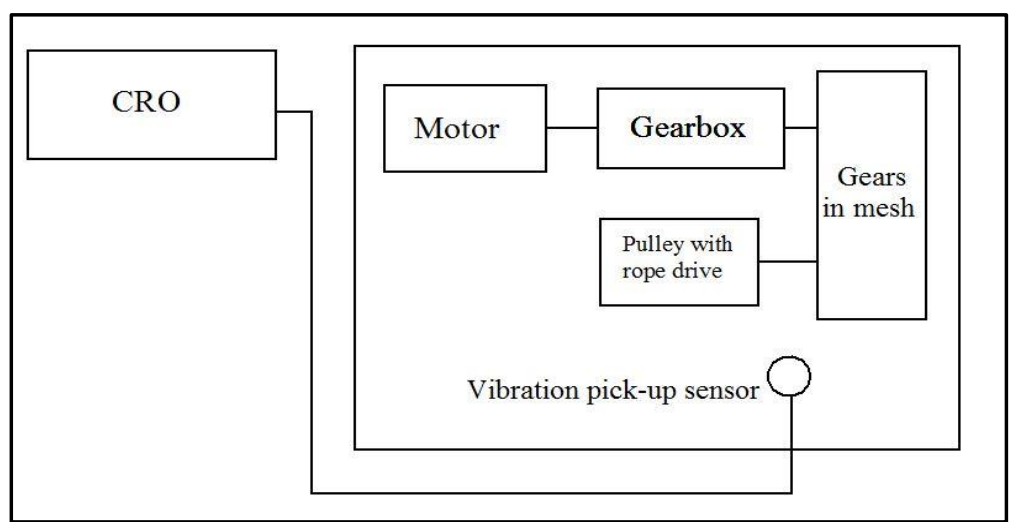

Figure 2: Block diagram of test set-up

The graph as described in Figure 3 provides a comparison of RMS vibration amplitude for coated and non-coated gears at the different load values. The gears were operated for four hours for each load condition.

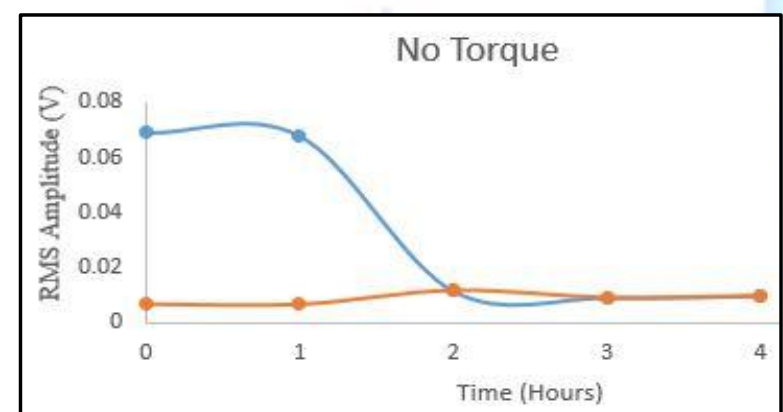

(a)

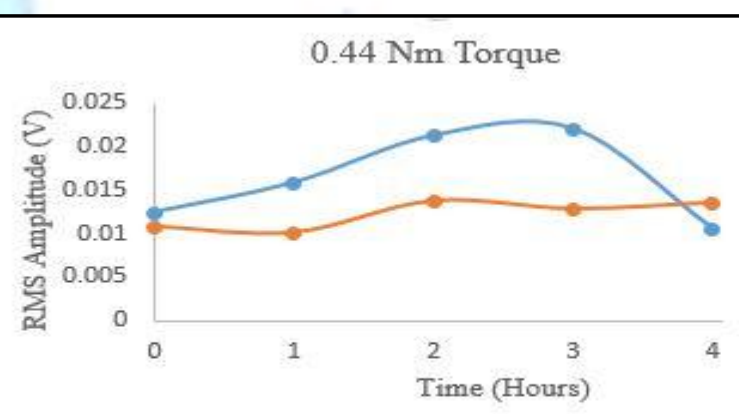

(b)

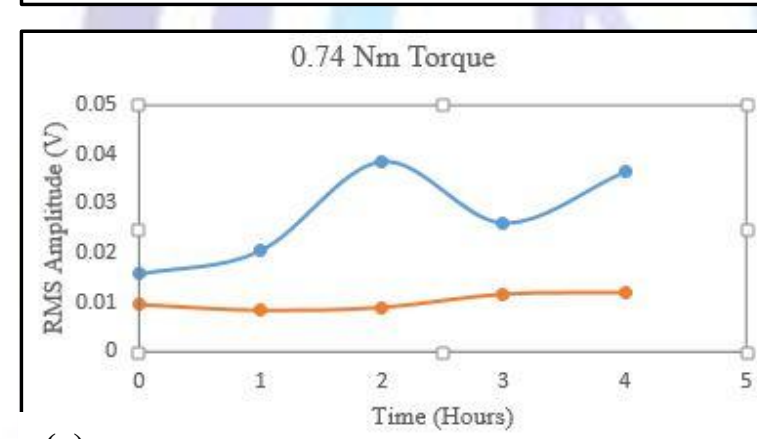

(c)

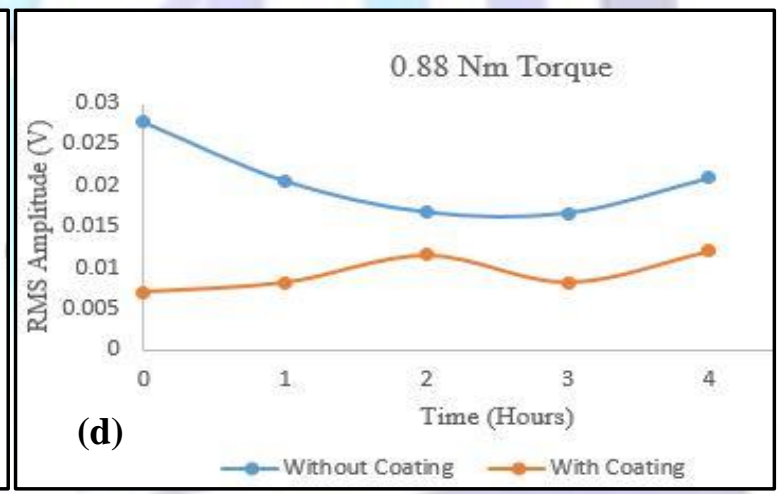

$1.32 \mathrm{Nm}$ Torque

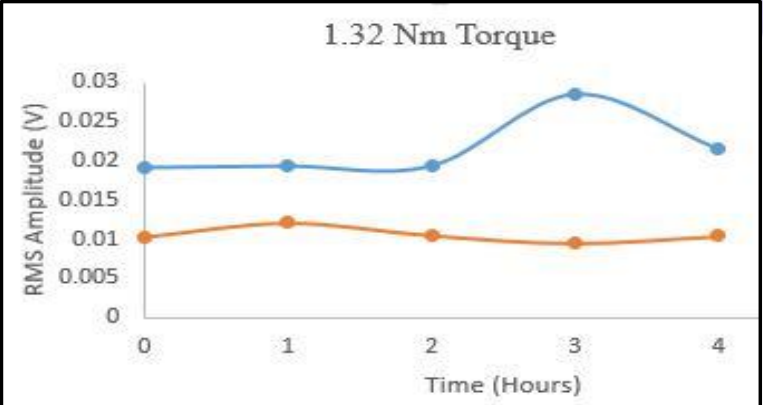

(e)

Figure 3: RMS Amplitude vs Time plots for (a) No Torque (b) $0.44 \mathrm{Nm}$ (c) $0.74 \mathrm{Nm}$ (d) $0.88 \mathrm{Nm}$ (e) $1.32 \mathrm{Nm}$

From the graphs shown in Figure 3, it can be clearly observed that the amplitude of vibration of coated gears is lesser than that of the non-coated gears. The vibration amplitude variation for coated gears is steady and more uniform with decreased peak values. 
The cause for decrease in vibration amplitude for all load conditions is accounted to decrease in sub-surface shear stress. Increase in surface hardness reduces fretting wear thereby reducing the shear stress. Decreased fretting wear makes the operation more smooth reducing the vibration amplitude.

\section{CONCLUSION}

- Characterization of sample plate through X-Ray diffraction plot confirmed the presence of Ni-WC crystal growth.

- The electro-deposition of $63 \mu \mathrm{m}$ of Ni-WC composite on the gear tooth surface increased the surface hardness by $8 \%$ for coated gears.

- Vibration analysis clearly indicated decrease in RMS amplitude by 36, 19.52, 59.30, 51.96 and $49.61 \%$ for the torque values of $0,0.44,0.74,0.88$ and $1.32 \mathrm{Nm}$ for coated gears compared to non-coated ones.

It was concluded that $\mathrm{Ni}-\mathrm{WC}$ composite coating of $63 \mu \mathrm{m}$ induced higher surface hardness and made the gears less prone to fretting. Lesser contact fatigue made the operation smoother thereby reducing the amplitude of vibration for coated gears.

\section{ACKNOWLEDGMENTS}

Our thanks to R\&D department of R.V. College of Engineering, Bengaluru for assisting us in the project and providing the necessary equipments.

\section{REFERENCES}

[1] Baragetti.S, Cavalleri.S, Tordini.F "A Numerical Method to Predict the RCF Behaviour of PVD-coated Transmission Gears and Experimental Results" - Procedia Engineering vol. 10 ,2011, pp.1485-1490

[2] BabakBakhit, AlirezaAkbari "Effect of particle size and co-deposition technique on hardness and corrosion properties of $\mathrm{Ni}-\mathrm{Co} / \mathrm{SiC}$ composite coatings", Surface \& Coatings Technology,2012, vol.206, pp 4964-4975

[3] Malathypushpavanam M, Balakrishnan K., "Electrodeposited Nickel composites for High Temperature Applications" Bulletin of Electrochemistry, Vol 1, (3), May-June 1985, pp.251-255

[4] Kodandarama L., Krishna M., Narasimha Murthy H. N., Sharma S.C., "Effect of Electro-Co-Deposition Parameters on Nickel Tungsten Carbide Composite Coatings" International Journal of Advanced Engineering Technology., Volume. II/ Issue IV/October-December, 2011, pp105-113

[5] Dhananjaykumar Singh, Manoj Kumar Tripathi, V. B. Singh - "Electrocodeposition and characterization of Ni-WC composite coating from non - aqueous bath" International Journal of Materials Science and Applications; Vol 2, (2), Published on January 10, 2013, pp 68-73

[6] GopalGundi, "Experimental Optimization of Electrodeposited Ni-SiC Composite Coating for Wear Behavior" Master's Thesis, Visvesvaraya Technological University, 2014

[7] Glaeser W.A., S.J.Shaffer, "Contact Fatigue”, ASM Handbook, Fatigue and Fracture, Volume 19, pp 331-336

[8] Cannon D.F., Pradier H., "Rail rolling contact fatigue Research by the European Rail Research Institute", Wear, vol. 191, 1996, pp 1-13

[9] Decker.H.J - "Crack Detection for Aerospace Quality Spur Gears" - International 58th Annual Forum and Technology Display, Montreal, Quebec, Canada, June 11-13, 2002

[10] S. Stewart, R. Ahmed, "Rolling contact fatigue of surface coatings—a review", Wear, Vol. 253, 2002, pp 1132-1144

[11] Jeffrey A Wheitner, Donald R. Houser, "Investigation of the Effects of Manufacturing Variations and Materials on Fatigue Crack Detection Methods in Gear Teeth", Report NAG3-1147, Lewis Research Center, January, 1995

\section{Author' biography with Photo}

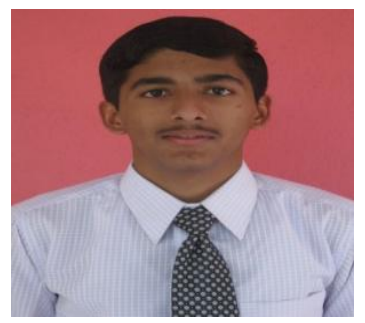

MR. KETAN BHAT,is a student of Mechanical Engineering, R.V. College of Engineering, Bengaluru. He was previously involved in the research of Smart Fluids and Rapid Prototyping. He is interested in the field ofDesign and Thermal Engineering. 

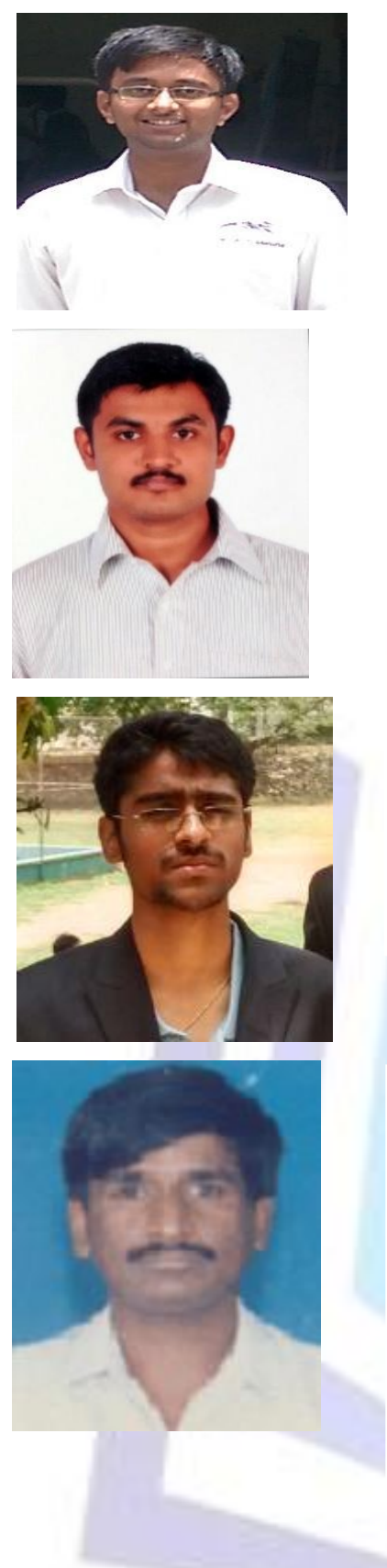

MR. MANEESH AVADHANI, is a student of Mechanical Engineering, R.V. College of Engineering, Bengaluru. He is a part of student supermileage team, Project Garuda. As a part of the team he participated in Shell Eco Marathon - Asia held at Manila, Philippines in February 2015. He is interested in thermal and automotive fields.

MR. MILIND GURAV,is a student of Mechanical Engineering, R.V. College of Engineering, Bengaluru. He has worked in the field of Rapid Prototyping,Magneto Rheological Fluids and Smart Fluids. He has interest in Fluid Mechanics and Material Science.

MR. VADIRAJ PATIL,is a student of Mechanical Engineering, R.V. College of Engineering, Bengaluru. He is a part of formula student team, Ashwa Racing. He has participated in Formula Student India held at Coimbatore, India. He plans to pursue his masters in Vehicle Dynamics.
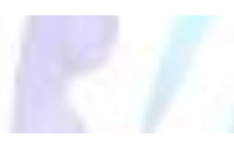

DR. M KRISHNA,He has acquired MS from BITS Pilani, Madhya Pradesh, India and Ph.D. in Materials Science, Mangalore University, Mangalore, India. He is working in the area of Composites, Alloys, Corrosion \& electroplating. He has published more than 100 research papers in international refereed journals; $\mathrm{He}$ is a recipient of $\mathrm{ARCl} B e s t \mathrm{Paper}$ Award \& Best Presentation Award, at NSSRS-4, 2002, IIT Madras, Chennai. Award of Who's Who, his name listed in Marquis Who's Who in Science and Technology, USA, 2004 and Living Science Award by International bio-graphical Centre, Cambridge, United Kingdom, 2004 for his contributions to the field of Research and Education. Presently he is the Director of CMRTU (R\&D) and Professor of Dept. of Mechanical Engg, R V College of Engg, Bangalore, India. 